\title{
Laparoscopic and robotic lateral lymph node dissection for rectal cancer
}

\author{
Ryota Nakanishi ${ }^{1} \cdot$ Tomohiro Yamaguchi $^{1} \cdot$ Takashi Akiyoshi $^{1} \cdot$ Toshiya Nagasaki $^{1}$ - Satoshi Nagayama ${ }^{1}$. \\ Toshiki Mukai $^{1} \cdot$ Masashi Ueno $^{1} \cdot$ Yosuke Fukunaga $^{1} \cdot$ Tsuyoshi Konishi $^{1}$
}

Received: 13 November 2019 / Accepted: 29 November 2019 / Published online: 27 January 2020

(c) The Author(s) 2020

\begin{abstract}
In the era of neoadjuvant chemoradiotherapy/radiotherapy and total mesorectal excision, overall oncological outcomes after curative resection of rectal cancer are excellent, with local recurrence rates as low as 5-10\%. However, lateral nodal disease is a major cause of local recurrence after neoadjuvant chemoradiotherapy/radiotherapy and total mesorectal excision. Patients with lateral nodal disease have a local recurrence rate of up to $30 \%$. The oncological benefits of lateral pelvic lymph node dissection (LPLND) in reducing local recurrence, particularly in the lateral compartment, have been demonstrated. Although LPLND is not standard in Western countries, technical improvements in minimally invasive surgery have resulted in rapid technical standardization of this complicated procedure. The feasibility and short- and long-term outcomes of laparoscopic and robotic LPLND have been reported widely. A minimally invasive approach has the advantages of less bleeding and providing a better surgical view of the deep pelvic anatomy than an open approach. With precise autonomic nerve preservation, postoperative genitourinary dysfunction has been reported to be minimal. We review recent evidence on the management of lateral nodal disease in rectal cancer and technical improvements of LPLND, focusing on laparoscopic and robotic LPLND.
\end{abstract}

Keywords Lateral lymph node dissection $\cdot$ Laparoscopic $\cdot$ Robotic $\cdot$ Rectal cancer

\section{Introduction}

Local recurrence of rectal cancer occurs as frequently as liver or lung metastases [1]. Its treatment can be challenging [2] and it impairs quality of life (QOL) with severe pelvic pain, foul-smelling discharge, and neurological disturbance, including tenesmus and incontinence. The Japanese Clinical Oncology Group reported on an RCT that evaluated mesenteric excision (ME) alone vs. ME plus prophylactic lateral pelvic lymph node dissection (LPLND) in patients with cStage II-III low rectal cancer without evident enlargement of the lateral nodes [3]. The 5-year relapse-free survival, being the primary endpoint of the study, was similar in the ME with LLND group and the ME alone group (73.4\% and $73.3 \%$, respectively), although the study failed to demonstrate non-inferiority of ME alone. Importantly, the study

Tsuyoshi Konishi

tkonishi-tky@umin.ac.jp

1 Department of Gastroenterological Surgery, Cancer Institute Hospital of the Japanese Foundation for Cancer Research, 31-8-3, Ariake, Koto-ku, Tokyo 135-8550, Japan found a higher local recurrence rate of $12.6 \%$ after ME alone vs. $7.4 \%$ after ME with LPLND $(p=0.024)$. These data clearly showed the oncological benefit of LPLND for reducing local recurrence of cStage II-III low rectal cancer even without suspicious lateral nodes. That study also identified longer operation times, greater blood loss, and a marginally higher rate of grade 3/4 complications in the ME with LLND group than in the ME alone group (21.7\% vs. $16.0 \%$, respectively; $p=0.07$ ) [4]. Sexual and urinary dysfunctions were not different in the two groups [5, 6].

In Western countries, neoadjuvant chemoradiotherapy/ radiotherapy (NACRT/RT) followed by total mesorectal excision (TME) is standard treatment for cStage II-III rectal cancer [7-9]. Although the overall local recurrence rate with this strategy is $5 \%$ to $10 \%[10,11]$, it has been demonstrated that patients with lateral nodal enlargement have a higher rate of local recurrence of up to $30 \%$ without LPLND [11]. With improved local control in the central pelvis by NACRT/RT and TME, there is emerging global attention on how to deal with lateral nodal disease as a major cause of local recurrence (Fig. 1) [11, 12]. With recent technical improvements in minimally invasive 


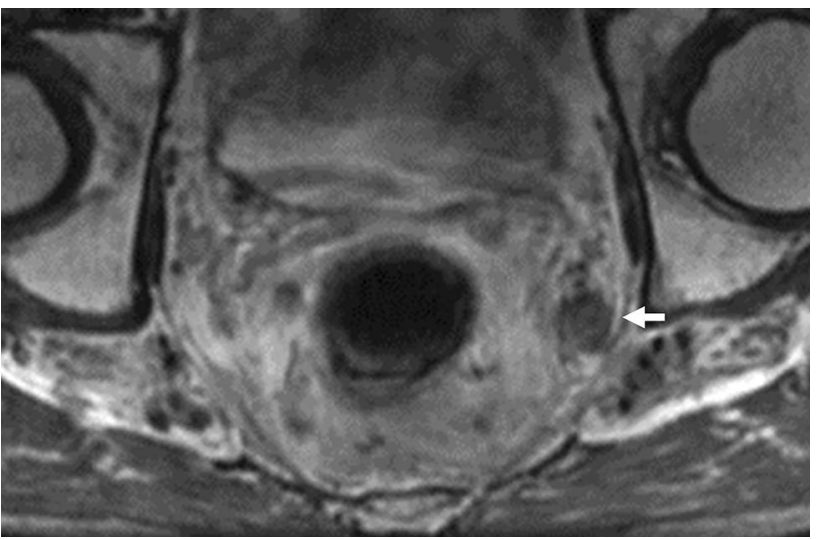

Fig. 1 Left lateral node metastasis in the obturator area

surgery, studies have demonstrated the safety and feasibility of LPLND through a minimally invasive approach $[13,14]$. In this article, we review recent evidence on the management of lateral nodal disease in rectal cancer and technical improvements in LPLND, with particular focus on laparoscopic and robotic LPLND.

Indications for selective lateral node dissection after neoadjuvant therapy. Lateral nodal disease is a major cause of local recurrence after NACRT/RT. In a study from Korea, the local recurrence rate after NACRT and TME reached $26.6 \%$ of patients with lateral nodes $\geq 5 \mathrm{~mm}$ in diameter and $68.8 \%$ of patients with lateral nodes $\geq 10 \mathrm{~mm}$ in diameter [15]. A multicenter international study found that lateral local recurrence rates after NACRT/RT in patients with enlarged lateral nodes $(\geq 7 \mathrm{~mm})$ were significantly lower in patients who underwent TME plus LPLND than in those who underwent TME alone $(5.7 \%$ vs. $19.5 \%$, respectively; $P=0.042$ ) [11]. These data suggest that preoperative CRT/RT is not sufficient to eliminate lateral nodal disease and that selective LPLND combined with preoperative CRT/RT should be considered for patients with lateral nodal disease.

Although the initial size of the lateral nodes before neoadjuvant therapy remains the gold standard for predicting lateral nodal disease [16], the role of post-treatment nodal size remains controversial. Akiyoshi et al. reported that a short-axis diameter of $\geq 8 \mathrm{~mm}$ in the lateral nodes before NACRT, female sex, and NACRT without induction chemotherapy was independently predictive of residual disease in the lateral nodes at final pathology, but that post-treatment size was not predictive [17]. In contrast, Ogura et al. reported the prognostic importance of the post-treatment size of the lateral nodes on restaging magnetic resonance imaging (MRI) after NACRT. Patients with post-treatment lateral nodes $<4 \mathrm{~mm}$ had no lateral local recurrence, whereas those with nodes $\geq 7 \mathrm{~mm}$ and/ or internal iliac nodes $\geq 5 \mathrm{~mm}$ had a 5 -year lateral local recurrence rate of 52.3\% [12]. The authors suggested that LPLND could be avoided for patients with lateral nodes that shrink with treatment.

In addition to node size, Brown et al. showed that the signal intensity and border characteristics of the nodes on MRI were associated with mesorectal nodal involvement [18]. The Mercury Study Group reported that patients with features suspicious of lateral node metastasis on pretreatment MRI, such as a spiculated border and mixed signal intensity, had worse 5-year disease-free survival than other patients (31\% vs. $76 \%$, respectively; $P=0.001)$ [19]. These findings suggest that malignant characteristics on MRI could add diagnostic value to the prediction of metastasis. Sex, T stage, histopathological grade, regional lymph node status, PET-CT status, and preoperative induction systemic chemotherapy are potential additional predictive factors to consider instead of the model based on MRI findings alone [17, 20, 21].

\section{Laparoscopic LPLND}

Multiple recent studies have been published on the feasibility of laparoscopic LPLND, short-term outcomes of which have been reported, mainly from Asian countries, since 2011 (Table 1) [13, 22-24]. Although these studies were retrospective case series, the short-term outcomes were reasonable, with median estimated blood [25] loss of $25-213 \mathrm{~mL}$ and rates of conversion of $0-17 \%$. Yamaguchi et al. reported a multicenter case-matched study that compared laparoscopic and open LPLND for stage II or III low rectal cancer [26]. They found that the laparoscopic group had a longer operation time (474 min vs. $363 \mathrm{~min}$ ), less blood loss ( $213 \mathrm{~mL}$ vs. $775 \mathrm{~mL})$, less blood transfusion (6.8\% vs. $22.2 \%$ ), similar rates of grade III or IV complications ( $23.7 \%$ vs. $22.9 \%$ ), and no mortality. Data on the longterm oncologic outcomes of this procedure are relatively limited. A case series of 107 patients who underwent laparoscopic LPLND after NACRT at a single cancer center in Japan reported 95.8\% 3-year overall survival, 84.7\% 3-year relapse-free survival, and a 3.2\% 3-year local recurrence rate [27]. The patients in that series all had cT3/4 extraperitoneal low rectal cancer with clinically positive lateral nodes; therefore, these data support the oncologic rationale for performing this procedure. A retrospective multicenter case-matched study from Japan, comparing laparoscopic and open LPLND reported 93.9\% 3-year overall survival, 93.9\% 3-year local recurrence-free survival, and $80.3 \%$ 3-year relapse-free survival in the laparoscopic group. These values were all similar to or better than those for the open group [26]. Although prospective validation studies are warranted, these outcomes indicate the technical safety and feasibility of laparoscopic LPLND. 
Table 1 Laparoscopic lateral pelvic lymph node dissection for rectal cancer

\begin{tabular}{lllllllll}
\hline Author & Year & $\begin{array}{l}\text { Number of } \\
\text { patients }\end{array}$ & $\begin{array}{l}\text { Neoadjuvant chem- } \\
\text { oradiotherapy } \%\end{array}$ & $\begin{array}{l}\text { Operation time } \\
\text { (total, min) }\end{array}$ & $\begin{array}{l}\text { Blood loss } \\
\text { (total, min) }\end{array}$ & $\begin{array}{l}\text { Number of har- } \\
\text { vested nodes }\end{array}$ & $\begin{array}{l}\text { Conversion } \\
\text { rate } \%\end{array}$ & $\begin{array}{l}\text { Overall } \\
\text { morbid- } \\
\text { ity } \%\end{array}$ \\
\hline Liu [22] & 2011 & 68 & N/A & 271 & 150 & 23 & N/A \\
Park [23] & 2011 & 16 & 56 & 310 & 188 & 9 & 0 & 7 \\
Liang [24] & 2011 & 34 & 100 & 58 & 44 & 6 & N/A & 21 \\
Konishi [13] & 2011 & 14 & 100 & 413 & 25 & 23 & 0 & 36 \\
Bae [25] & 2014 & 21 & 86 & 396 & 200 & 7 & 0 & 29 \\
Ogura [27] & 2016 & 107 & 100 & 461 & 115 & 25 & 0 & 34 \\
Yamaguchi [26] & 2017 & 118 & 24 & 474 & 213 & 10 & 17 & 41 \\
Aisu [28] & 2018 & 25 & 76 & 558 & 100 & N/A & 0 \\
\hline
\end{tabular}

N/A Not assessed

\section{Robotic LPLND}

Robotic LPLND was first described by Park et al., who reported a series of eight patients [29], since when other authors have documented their results (Table 2) [30-35]. Robotic surgery has the advantages of using multi-joint forceps with a motion scaling, high-quality three-dimensional camera and greatly improved ergonomics, which are all ideal for complex procedures such as LPLND. Yamaguchi et al. reported the short- and long-term oncological outcomes of robotic vs. open LPLND $[32,34]$. Robotic LPLND was associated with less blood loss $(25 \mathrm{~mL}$ vs. $637 \mathrm{~mL}, P<0.001)$, less need for blood transfusion ( $0 \%$ vs. $10.2 \%, P=0.003)$, longer operative time (455 min vs. $410 \mathrm{~min}, P=0.007$ ), and fewer postoperative complications (wound infection $0 \%$ vs. $8.0 \%, P=0.014$; small bowel obstruction $3.5 \%$ vs. $15.9 \%$, $P=0.009$; anastomotic leakage $0 \%$ vs. $9.1 \%, P=0.007$; urinary retention $18.8 \%$ vs. $36.4 \%, P=0.011$ ) than the open procedure. That study also reported similar 5-year overall survival rates $(95.4 \%$ vs. $87.8 \%$, respectively; $P=0.106)$ and 5-year relapse-free survival rates $(79.1 \%$ vs. $69.9 \%$, $P=0.157)$ for robotic LPLND and the open procedure, but noted that robotic LPLND had superior 5-year local relapsefree survival $(98.6 \%$ vs. $90.9 \%, P=0.029)$. Kim et al. compared the short-term outcomes of robotic vs. laparoscopic
LPLND [35]. Whereas the operative time was similar in the two groups, the estimated blood loss and the incidence of Foley catheter reinsertion for urinary retention after surgery were lower in the robotic group. Overall and local recurrence rates did not differ between the groups. Although there is limited evidence directly comparing robotic and laparoscopic LPLND, a robotic approach is generally regarded as a reasonable alternative for this complicated procedure, particularly in Western countries where LPLND is not standard.

\section{Technical procedures}

The technical procedures of laparoscopic LPLND are well established and have been standardized by multiple authors $[13,36]$. The important advantage of laparoscopic LPLND is a better surgical view within the deep pelvis, which allows for identification of the pelvic vessels and autonomic nerves (Fig. 2a). Typically, LPLND should be performed after completion of TME and before anastomosis. No additional trocars are needed after TME. The obturator and internal iliac nodes are the most important to dissect because they cover most of the curable lateral node metastasis from rectal cancer. To dissect these two areas, three planes should be recognized: the lateral pelvic wall plane, which is composed of the psoas and internal obturator muscles; the medial plane,

Table 2 Robotic lateral pelvic lymph node dissection for rectal cancer

\begin{tabular}{|c|c|c|c|c|c|c|c|c|}
\hline Author & Year & $\begin{array}{l}\text { Number of } \\
\text { patients }\end{array}$ & $\begin{array}{l}\text { Neoadjuvant chem- } \\
\text { oradiotherapy } \%\end{array}$ & $\begin{array}{l}\text { Operation time } \\
\text { (total, min) }\end{array}$ & $\begin{array}{l}\text { Blood loss } \\
\text { (total, min) }\end{array}$ & $\begin{array}{l}\text { Number of har- } \\
\text { vested nodes }\end{array}$ & $\begin{array}{l}\text { Conversion } \\
\text { rate } \%\end{array}$ & $\begin{array}{l}\text { Overall } \\
\text { morbid- } \\
\text { ity } \%\end{array}$ \\
\hline Park [29] & 2012 & 8 & 100 & 272 & 45 & 4.1 & 0 & 25 \\
\hline Yamaguchi [32] & 2016 & 85 & 12 & 455 & 25 & 19 & 0 & 31 \\
\hline Shin [33] & 2016 & 16 & 100 & 401 & 125 & 2.5 & 0 & 39 \\
\hline Kim [35] & 2018 & 50 & 86 & 260 & 34.6 & 6.6 & 0 & 28 \\
\hline
\end{tabular}

N/A Not assessed 
Fig. 2 a Laparoscopic view of the anatomy of the lateral area after lateral node dissection. b Dissection planes for lateral node dissection. c Vesicohypogastric fascia (dotted line), which divides the lateral area into the obturator (blue) and internal iliac (green) compartments. Abbreviations: sup superior, inf inferior, int internal, ext external, $a$ artery, $v$ vein, $n$ nerve, $m$ muscle
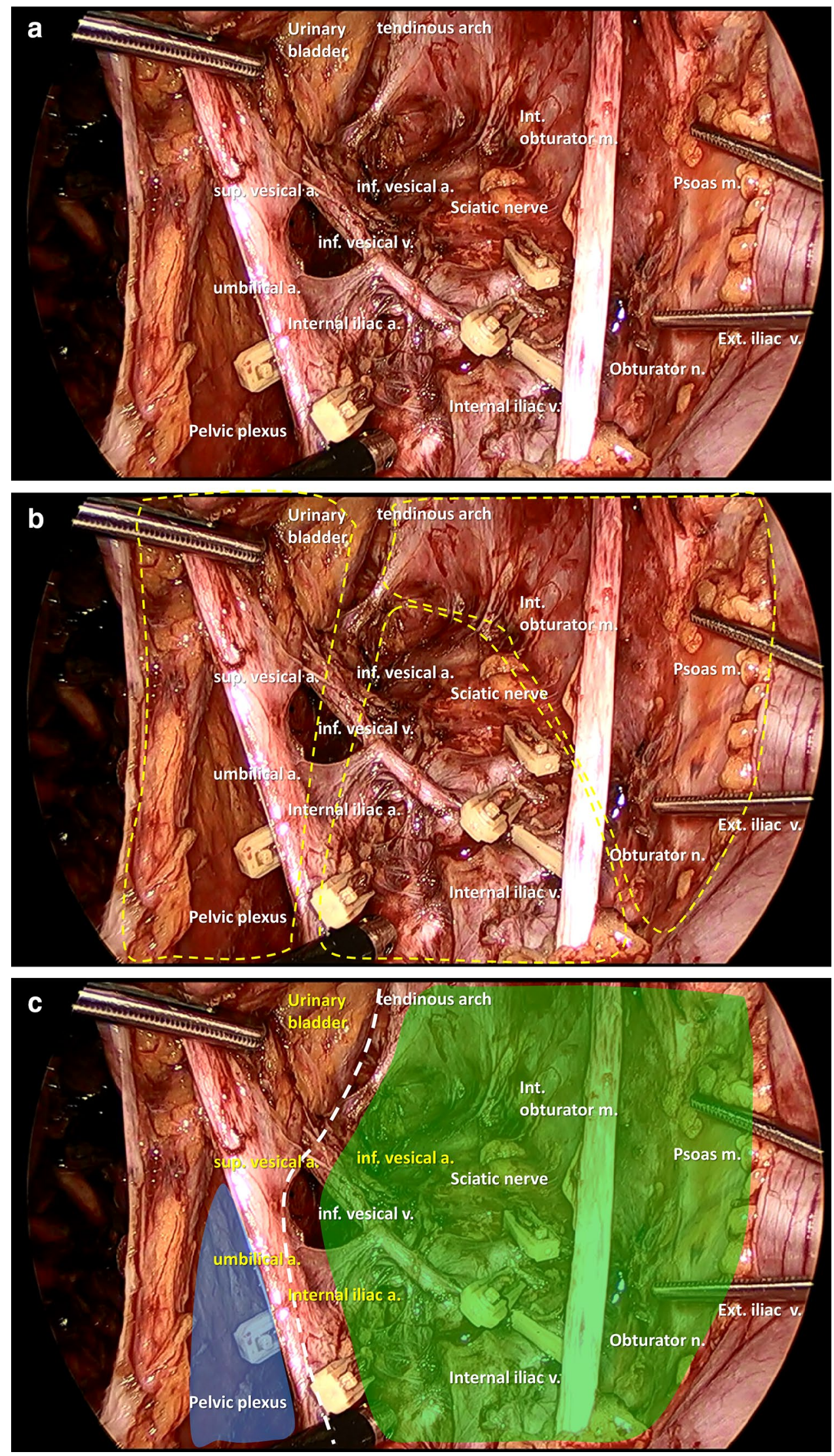
composed of the ureter and the pelvic plexus; and the dorsal plane, composed of the internal iliac vessels and the sciatic nerve (Fig. 2b). These three planes surround the area to be dissected. Another important plane divides the area into the obturator and internal iliac compartments: the vesicohypogastric fascia, composed of the bladder, internal iliac artery, and the urinary branches (the umbilical and superior vesical and inferior vesical arteries; Fig. 2c). Dissection along these planes minimizes bleeding and prevents incomplete dissection in LPLND.

\section{Postoperative complications}

The reported postoperative complication rates of laparoscopic and robotic LPLND range from 7 to $41 \%$ and 25 to $39 \%$, respectively (Table 3) [13, 22-29, 32, 33, 35]. These rates are equal to or lower than the complication rates after open procedures $[3,26,32]$. Ogura et al. reported that the incidence of major complications (grade $\geq 3$ ) after laparoscopic LPLND was 9.3\%, including anastomotic leakage, pelvic abscess, ileus and postoperative bleeding [27]. Bae et al. reported a postoperative complication rate of $28 \%$ after laparoscopic or robotic LPLND, including anastomotic leakage, ileus and chyle leakage [25]. Kim et al. compared the short-term outcomes of laparoscopic and robotic LPLND and found that the incidences of postoperative complications were similar (28\% vs. $34 \%$, respectively; $P=0.63$ ) [35]. Yamaguchi et al. reported that the rates of wound infection, small-bowel obstruction, and anastomotic leakage after robotic LPLND were lower than those after open LPLND $(P<0.05$ for all $)[32]$.

Postoperative urinary and sexual dysfunction are major complications after rectal surgery and the addition of LPLND has been reported to result in more genitourinary dysfunction than TME alone [37-42]. However, nerve-preserving techniques minimize this dysfunction after LPLND $[43,44]$. A recent Japanese RCT reported similar rates of sexual and urinary dysfunction after TME alone vs. TME plus LPLND through an open approach (male sexual dysfunction, $68 \%$ vs. $79 \%$, respectively; $P=0.37$; subclinical urinary dysfunction with $\geq 50 \mathrm{~mL}$ residual urine, $59 \%$ vs. $58 \%$, respectively) $[5,6]$. The authors concluded that if

Table 3 Postoperative genitourinary dysfunction after lateral lymph node dissection for rectal cancer

\begin{tabular}{|c|c|c|c|c|c|c|}
\hline Author & Year & $\begin{array}{l}\text { Num- } \\
\text { ber of } \\
\text { patients }\end{array}$ & ANP & Surgical procedure & Urinary function & Sexual function \\
\hline Sugihara [38] & 1996 & 214 & Yes & Open & & $\begin{array}{l}29.6 \% \text { male sexual dysfuction } \\
\text { (Bilateral ANP) } 33.3 \% \text { no erection } \\
\text { (removal of the hypogastric nerves) }\end{array}$ \\
\hline Matsuoka [39] & 2001 & 83 & N/A & Open & $\begin{array}{l}86 \% \text { dysuria } 40 \% \text { urinary inconti- } \\
\text { nence } 25 \% \text { need CIC for more than } \\
3 \text { years }\end{array}$ & \\
\hline Maeda [40] & 2003 & 65 & Yes & Open & $\begin{array}{l}15 \% \text { minor disturbance ( } 25 \% \text { without } \\
\text { LPLND) }\end{array}$ & $\begin{array}{l}27 \% \text { impotency ( } 20 \% \text { without LPLND) } \\
11 \% \text { retrograde ejaculation ( } 25 \% \\
\text { without LPLND) }\end{array}$ \\
\hline Col [41] & 2005 & 24 & N/A & Open & $\begin{array}{l}58 \% \text { urinary incontinence ( } 39 \% \text { with- } \\
\text { out LPLND) } 16 \% \text { urinary retention } \\
\text { (4\% without LPLND) }\end{array}$ & \\
\hline Akasu [42] & 2009 & 42 & Yes/No & Open & & $\begin{array}{l}44 \%, 44 \%, 100 \% \text { no erection (Bilateral } \\
\text { ANP, unilateral ANP, no ANP) } \\
0 \%, 50 \%, 100 \% \text { no ejaculation (Bilat- } \\
\text { eral ANP, unilateral ANP, no ANP) }\end{array}$ \\
\hline Saito [5] & 2016 & 701 & Yes & Open & & $\begin{array}{l}79 \% \text { sexual dysfuction ( } 68 \% \text { without } \\
\text { LPLND) }\end{array}$ \\
\hline Ito [6] & 2018 & 701 & Yes & Open & $\begin{array}{l}59 \% \text { urinary incontinence ( } 58 \% \\
\text { without LPLND) }\end{array}$ & \\
\hline Liu [45] & 2013 & 60 & Yes & Laparoscopic & $\begin{array}{l}78 \% \text { incomplete emptying } 70 \% \\
\text { frequency }\end{array}$ & \\
\hline Ogura [27] & 2016 & 107 & Yes & Laparoscopic & $\begin{array}{l}5 \% \text { urinary retention requiring CIC } \\
(1.5 \% \text { without LPLND) }\end{array}$ & \\
\hline Yamaguchi [32] & 2016 & 85 & Yes & Robotic & $\begin{array}{l}18.8 \% \text { and } 36.4 \% \text { urinary retention in } \\
\text { robotic and open LPLND }\end{array}$ & \\
\hline $\operatorname{Kim}[35]$ & 2018 & 50 & Yes & Robotic & $\begin{array}{l}4 \% \text { and } 20 \% \text { urinary retention in } \\
\text { robotic and Laparoscopic LPLND }\end{array}$ & \\
\hline
\end{tabular}

ANP autonomic nerve preservation, N/A not assessed, CIC clean intermittent catheterization, LPLND lateral pelvic lymph node dissection 
autonomic nerve-preserving procedures are done, LPLND does not increase the risk of sexual or urinary dysfunction. A few studies have investigated genitourinary dysfunction after laparoscopic and robotic LPLND. Liu et al. reported adequate urinary function after laparoscopic LPLND [45]. At a high-volume center in Japan with experienced laparoscopic surgeons, the incidence of postoperative urinary dysfunction was minimal $[13,27]$. Manabe et al. reported that combined resection of the bilateral inferior vesical arteries was a risk factor for postoperative urinary dysfunction after laparoscopic LPLND [46]. It should be noted that not only the autonomic nerves but also the inferior vesical arteries are closely associated with functional outcomes after LPLND. Although the data are limited, robotic LPLND may allow for better handling of these structures, resulting in a lower incidence of postoperative genitourinary dysfunction than after open or laparoscopic LPLND [32, 35]. The risk of postoperative complications after LPLND is influenced by multiple factors, including whether the procedure is prophylactic or definitive and unilateral or bilateral. Case-matched prospective validation studies are needed to investigate this further.

\section{Conclusion}

In the era of NACRT/RT, selective LPLND provides oncological benefits to patients with suspicious lateral nodes, particularly for reducing local recurrence. Careful patient selection and the appropriate use of minimally invasive surgery have the potential to improve short-term and long-term outcomes. Further studies are warranted to promote the minimally invasive approach for LPLND, including its technical feasibility in a larger dataset, complication profiles, leaning curve, continence, urinary/sexual function, and oncologic long-term outcomes.

\section{Compliance with ethical standards}

Conflicts of interest We have no conflicts of interest to declare.

Open Access This article is licensed under a Creative Commons Attribution 4.0 International License, which permits use, sharing, adaptation, distribution and reproduction in any medium or format, as long as you give appropriate credit to the original author(s) and the source, provide a link to the Creative Commons licence, and indicate if changes were made. The images or other third party material in this article are included in the article's Creative Commons licence, unless indicated otherwise in a credit line to the material. If material is not included in the article's Creative Commons licence and your intended use is not permitted by statutory regulation or exceeds the permitted use, you will need to obtain permission directly from the copyright holder. To view a copy of this licence, visit http://creativecommons.org/licenses/by/4.0/.

\section{References}

1. Faerden AE, Naimy N, Wiik P, Reiertsen O, Weyessa S, Tronnes $S$, et al. Total mesorectal excision for rectal cancer: difference in outcome for low and high rectal cancer. Dis Colon Rectum. 2005;48(12):2224-31.

2. Enriquez-Navascues JM, Borda N, Lizerazu A, Placer C, Elosegui $\mathrm{JL}$, Ciria JP, et al. Patterns of local recurrence in rectal cancer after a multidisciplinary approach. World J Gastroenterol. 2011;17(13):1674-84.

3. Fujita S, Mizusawa J, Kanemitsu Y, Ito M, Kinugasa Y, Komori $\mathrm{K}$, et al. Mesorectal excision with or without lateral lymph node dissection for clinical stage II/III lower rectal cancer (JCOG0212): a multicenter, randomized controlled noninferiority trial. Ann Surg. 2017;266(2):201-7.

4. Fujita S, Akasu T, Mizusawa J, Saito N, Kinugasa Y, Kanemitsu Y, et al. Postoperative morbidity and mortality after mesorectal excision with and without lateral lymph node dissection for clinical stage II or stage III lower rectal cancer (JCOG0212): results from a multicentre, randomised controlled, non-inferiority trial. Lancet Oncol. 2012;13(6):616-21.

5. Saito S, Fujita S, Mizusawa J, Kanemitsu Y, Saito N, Kinugasa $\mathrm{Y}$, et al. Male sexual dysfunction after rectal cancer surgery: Results of a randomized trial comparing mesorectal excision with and without lateral lymph node dissection for patients with lower rectal cancer: japan clinical oncology group study JCOG0212. Eur J Surg Oncol. 2016;42(12):1851-8.

6. Ito M, Kobayashi A, Fujita S, Mizusawa J, Kanemitsu Y, Kinugasa Y, et al. Urinary dysfunction after rectal cancer surgery: Results from a randomized trial comparing mesorectal excision with and without lateral lymph node dissection for clinical stage II or III lower rectal cancer (Japan clinical oncology group study, JCOG0212). Eur J Surg Oncol. 2018;44(4):463-8.

7. Kapiteijn E, Marijnen CA, Nagtegaal ID, Putter H, Steup WH, Wiggers T, et al. Preoperative radiotherapy combined with total mesorectal excision for resectable rectal cancer. N Engl J Med. 2001;345(9):638-46.

8. Sauer R, Becker H, Hohenberger W, Rodel C, Wittekind C, Fietkau R, et al. Preoperative versus postoperative chemoradiotherapy for rectal cancer. N Engl J Med. 2004;351(17):1731-40.

9. Bosset JF, Collette L, Calais G, Mineur L, Maingon P, Radosevic-Jelic L, et al. Chemotherapy with preoperative radiotherapy in rectal cancer. N Engl J Med. 2006;355(11):1114-23.

10. Ahmad NZ, Ahmed A. Rigid or flexible sigmoidoscopy in colorectal clinics? Appraisal through a systematic review and metaanalysis. J Laparoendosc Adv Surg Tech A. 2012;22(5):479-87.

11. Ogura A, Konishi T, Cunningham C, Garcia-Aguilar J, Iversen $\mathrm{H}$, Toda $\mathrm{S}$, et al. Neoadjuvant (Chemo) radiotherapy with total mesorectal excision only is not sufficient to prevent lateral local recurrence in enlarged nodes: results of the multicenter lateral node study of patients with low cT3/4 rectal cancer. J Clin Oncol. 2019;37(1):33-43.

12. Ogura A, Konishi T, Beets GL, Cunningham C, Garcia-Aguilar $\mathrm{J}$, Iversen $\mathrm{H}$, et al. Lateral nodal features on restaging magnetic resonance imaging associated with lateral local recurrence in low rectal cancer after neoadjuvant chemoradiotherapy or radiotherapy. JAMA Surg. 2019. https://doi.org/10.1001/jamas urg.2019.2172.

13. Konishi T, Kuroyanagi H, Oya M, Ueno M, Fujimoto Y, Akiyoshi $\mathrm{T}$, et al. Multimedia article. Lateral lymph node dissection with preoperative chemoradiation for locally advanced lower rectal cancer through a laparoscopic approach. Surg Endosc. 2011;25(7):2358-9.

14. Akiyoshi T, Ueno M, Matsueda K, Konishi T, Fujimoto Y, Nagayama $\mathrm{S}$, et al. Selective lateral pelvic lymph node dissection in 
patients with advanced low rectal cancer treated with preoperative chemoradiotherapy based on pretreatment imaging. Ann Surg Oncol. 2014;21(1):189-96.

15. Kim TG, Park W, Choi DH, Park HC, Kim SH, Cho YB, et al. Factors associated with lateral pelvic recurrence after curative resection following neoadjuvant chemoradiotherapy in rectal cancer patients. Int J Colorectal Dis. 2014;29(2):193-200.

16. Kim JH, Beets GL, Kim MJ, Kessels AG, Beets-Tan RG. High-resolution MR imaging for nodal staging in rectal cancer: are there any criteria in addition to the size? Eur J Radiol. 2004;52(1):78-83.

17. Akiyoshi T, Matsueda K, Hiratsuka M, Unno T, Nagata J, Nagasaki $\mathrm{T}$, et al. Indications for lateral pelvic lymph node dissection based on magnetic resonance imaging before and after preoperative chemoradiotherapy in patients with advanced low-rectal cancer. Ann Surg Oncol. 2015;22(Suppl 3):S614-S620620.

18. Brown G, Richards CJ, Bourne MW, Newcombe RG, Radcliffe AG, Dallimore NS, et al. Morphologic predictors of lymph node status in rectal cancer with use of high-spatial-resolution MR imaging with histopathologic comparison. Radiology. 2003;227(2):371-7.

19. Group MS, Shihab OC, Taylor F, Bees N, Blake H, Jeyadevan $\mathrm{N}$, et al. Relevance of magnetic resonance imaging-detected pelvic sidewall lymph node involvement in rectal cancer. Br J Surg. 2011;98(12):1798-804.

20. Ogawa S, Hida JI, Ike H, Kinugasa T, Ota M, Shinto E, et al. Prediction of lateral pelvic lymph node metastasis from lower rectal cancer using magnetic resonance imaging and risk factors for metastasis: multicenter study of the lymph node committee of the japanese society for cancer of the colon and rectum. Int $\mathrm{J}$ Colorectal Dis. 2017;32(10):1479-87.

21. Matsuda T, Sumi Y, Yamashita K, Hasegawa H, Yamamoto M, Matsuda Y, et al. Outcomes and prognostic factors of selective lateral pelvic lymph node dissection with preoperative chemoradiotherapy for locally advanced rectal cancer. Int J Colorectal Dis. 2018;33(4):367-74.

22. Liu T, Zhang C, Yu P, Chen J, Zeng D, Gan L, et al. Laparoscopic radical correction combined with extensive lymphadenectomy and pelvic autonomic nerve preservation for mid-to-low rectal cancer. Clin Colorectal Cancer. 2011;10(3):183-7.

23. Park JS, Choi GS, Lim KH, Jang YS, Kim HJ, Park SY, et al. Laparoscopic extended lateral pelvic node dissection following total mesorectal excision for advanced rectal cancer: initial clinical experience. Surg Endosc. 2011;25(10):3322-9.

24. Liang JT. Technical feasibility of laparoscopic lateral pelvic lymph node dissection for patients with low rectal cancer after concurrent chemoradiation therapy. Ann Surg Oncol. 2011;18(1):153-9.

25. Bae SU, Saklani AP, Hur H, Min BS, Baik SH, Lee KY, et al. Robotic and laparoscopic pelvic lymph node dissection for rectal cancer: short-term outcomes of 21 consecutive series. Ann Surg Treat Res. 2014;86(2):76-82.

26. Yamaguchi T, Konishi T, Kinugasa Y, Yamamoto S, Akiyoshi T, Okamura R, et al. Laparoscopic versus open lateral lymph node dissection for locally advanced low rectal cancer: a subgroup analysis of a large multicenter cohort study in Japan. Dis Colon Rectum. 2017;60(9):954-64.

27. Ogura A, Akiyoshi T, Nagasaki T, Konishi T, Fujimoto Y, Nagayama $\mathrm{S}$, et al. Feasibility of laparoscopic total mesorectal excision with extended lateral pelvic lymph node dissection for advancedlower rectal cancer after preoperative chemoradiotherapy. World J Surg. 2017;41(3):868-75.

28. Aisu Y, Kato S, Kadokawa Y, Yasukawa D, Kimura Y, Takamatsu Y, et al. Feasibility of extended dissection of lateral pelvic lymph nodes during laparoscopic total mesorectal excision in patients with locally advanced lower rectal cancer: a single-center pilot study after neoadjuvant chemotherapy. Med Sci Monit. 2018;24:3966-77.

29. Park JA, Choi GS, Park JS, Park SY. Initial clinical experience with robotic lateral pelvic lymph node dissection for advanced rectal cancer. J Korean Soc Coloproctol. 2012;28(5):265-70.

30. Kagawa H, Kinugasa Y, Shiomi A, Yamaguchi T, Tsukamoto S, Tomioka H, et al. Robotic-assisted lateral lymph node dissection for lower rectal cancer: short-term outcomes in 50 consecutive patients. Surg Endosc. 2015;29(4):995-1000.

31. Sasi S, Rohila J, Kammar P, Kurunkar S, Desouza A, Saklani A. Robotic lateral pelvic lymph node dissection in rectal cancer - a video vignette. Colorectal Dis. 2018;20(6):554-5.

32. Yamaguchi T, Kinugasa Y, Shiomi A, Tomioka H, Kagawa H. Robotic-assisted laparoscopic versus open lateral lymph node dissection for advanced lower rectal cancer. Surg Endosc. 2016;30(2):721-8.

33. Shin US, Nancy You Y, Nguyen AT, Bednarski BK, Messick C, Maru DM, et al. Oncologic outcomes of extended robotic resection for rectal cancer. Ann Surg Oncol. 2016;23(7):2249-57.

34. Yamaguchi T, Kinugasa Y, Shiomi A, Kagawa H, Yamakawa Y, Furutani A, et al. Oncological outcomes of robotic-assisted laparoscopic versus open lateral lymph node dissection for locally advanced low rectal cancer. Surg Endosc. 2018;32(11):4498-505.

35. Kim HJ, Choi GS, Park JS, Park SY, Lee HJ, Woo IT, et al. Selective lateral pelvic lymph node dissection: a comparative study of the robotic versus laparoscopic approach. Surg Endosc. 2018;32(5):2466-73.

36. Perez RO, Sao Juliao GP, Vailati BB, Fernandez LM, Mattacheo AE, Konishi T. Lateral node dissection in rectal cancer in the era of minimally invasive surgery: a step-by-step description for the surgeon unacquainted with this complex procedure with the use of the laparoscopic approach. Dis Colon Rectum. 2018;61(10):1237-40.

37. Santangelo ML, Romano G, Sassaroli C. Sexual function after resection for rectal cancer. Am J Surg. 1987;154(5):502-4.

38. Sugihara K, Moriya Y, Akasu T, Fujita S. Pelvic autonomic nerve preservation for patients with rectal carcinoma Oncologic and functional outcome. Cancer. 1996;78(9):1871-80.

39. Matsuoka N, Moriya Y, Akasu T, Fujita S. Long-term outcome of urinary function after extended lymphadenectomy in patients with distal rectal cancer. Eur J Surg Oncol. 2001;27(2):165-9.

40. Maeda K, Maruta M, Utsumi T, Sato H, Toyama K, Matsuoka H. Bladder and male sexual functions after autonomic nerve-sparing TME with or without lateral node dissection for rectal cancer. Tech Coloproctol. 2003;7(1):29-33.

41. Col C, Hasdemir O, Yalcin E, Guzel H, Tunc G, Bilgen K, et al. The assessment of urinary function following extended lymph node dissection for colorectal cancer. Eur J Surg Oncol. 2005;31(3):237-41.

42. Akasu T, Sugihara K, Moriya Y. Male urinary and sexual functions after mesorectal excision alone or in combination with extended lateral pelvic lymph node dissection for rectal cancer. Ann Surg Oncol. 2009;16(10):2779-866.

43. Masui H, Ike H, Yamaguchi S, Oki S, Shimada H. Male sexual function after autonomic nerve-preserving operation for rectal cancer. Dis Colon Rectum. 1996;39(10):1140-5.

44. Kim NK, Aahn TW, Park JK, Lee KY, Lee WH, Sohn SK, et al. Assessment of sexual and voiding function after total mesorectal excision with pelvic autonomic nerve preservation in males with rectal cancer. Dis Colon Rectum. 2002;45(9):1178-85.

45. Liu LY, Liu WH, Cao YK, Zhang L, Wang PH, Tang LJ. Urinary function following laparoscopic lymphadenectomy for male rectal cancer. PLoS ONE ONE. 2013;8(11):e78701. 
46. Manabe T, Koga Y, Kubo H, Baba K, Nagayoshi K, Nagai S, et al. Adverse effects on the postoperative urinary function after combined resection of inferior vesical artery in laparoscopic lateral pelvic lymph node dissection: retrospective analysis of consecutive 95 series. Surg Laparosc Endosc Percutan Tech. 2019;29(6):493-54949.
Publisher's Note Springer Nature remains neutral with regard to jurisdictional claims in published maps and institutional affiliations. 